\title{
Alzheimer's Disease-like Alterations in Peripheral Cells from Presenilin-1 Transgenic Mice
}

\author{
Anne Eckert,, ${ }^{* 1}$ Katharina Schindowski, ${ }^{*}$ Silke Leutner, ${ }^{*}$ \\ Christian Luckhaus, ${ }^{*}$ Nathalie Touchet, ${ }^{+}$Christian Czech, ${ }^{+, 2}$ \\ and Walter E. Müller* \\ *Department of Pharmacology, Biocenter, University of Frankfurt, Marie-Curie-Strasse 9, \\ D-60439 Frankfurt, Germany; and ${ }^{\dagger}$ Aventis Pharma, Research and Development, \\ 13 Quai Jules Guesde, F-94403 Vitry-sur-Seine, France
}

Received August 23, 2000; revised October 10, 2000; accepted November 28, 2000; published online February 17, 2001

\begin{abstract}
Many cases of early-onset inherited Alzheimer's disease (AD) are caused by mutations in the presenilin-1 (PS1) gene. Expression of PS1 mutations in cell culture systems and in primary neurons from transgenic mice increases their vulnerability to cell death. Interestingly, enhanced vulnerability to cell death has also been demonstrated for peripheral lymphocytes from AD patients. We now report that lymphocytes from PS1 mutant transgenic mice show a similar hypersensitivity to cell death as do peripheral cells from AD patients and several cell culture systems expressing PS1 mutations. The cell death-enhancing action of mutant PS1 was associated with increased production of reactive oxygen species and altered calcium regulation, but not with changes of mitochondrial cytochrome c. Our study further emphasizes the pathogenic role of mutant PS1 and may provide the fundamental basis for new efforts to close the gap between studies using neuronal cell lines transfected with mutant PS1, neurons from transgenic animals, and peripheral cells from AD patients. $\odot 2001$ Academic Press

Key Words: Alzheimer's disease; presenilin-1; cell death; calcium; oxidative stress; lymphocytes; cytochrome c.
\end{abstract}

\section{INTRODUCTION}

Alzheimer's disease (AD) is the leading cause of age-related dementia. Certain familial forms of AD (FAD) are characterized by an autosomal-dominant inheritance pattern and an extremely early age of onset. The majority of them have been linked to missense mutations in the PS1 gene (Sherrington et al., 1995; Czech et al., 2000). The precise mechanism by which PS1 mutations lead to neurodegeneration in AD remains still to be identified, but seem to be associated with altered proteolytic processing of amyloid precursor protein (APP) and enhanced production of the amyloidogenic form of $\beta$-amyloid $(\mathrm{A} \beta) \quad 1-42$ (Scheuner et al., 1996; Citron et al., 1997). Recent find-

\footnotetext{
${ }^{1}$ To whom correspondence should be addressed. Fax: (49) 69 79829374. E-mail: A.Eckert@em.uni-frankfurt.de.

${ }^{2}$ Present address: NAP AG, Munich, Germany.
}

ings indicate that the expression of mutant PS1 (PS1 L286V) in PC12 cells or the PS1 exon 9 deletion in neuroblastoma cells sensitizes cells to apoptosis (Guo et al., 1997; Tanii et al., 2000). In addition, cultures of primary hippocampal neurons from PS1 mutant knock-in mice (PS1 M146KI) show increased vulnerability to cell death, increased oxidative stress, and mitochondrial dysfunction (Guo et al., 1999b). A recent study further reported that PS1 mutations increase calcium release in transfected cell lines or cortical neurons from PS1 M146KI mice (Chan et al., 2000). In addition, lymphocyte cell lines, e.g., the human Jurkat T-cell line, transfected with mutant PS1 (Passer et al., 1999) and lymphocytes from FAD patients bearing PS1 mutations (Parshad et al., 1996) show similar results in regard to increased vulnerability to DNA damage finally leading to accelerated cell death. Moreover, enhanced vulnerability to cell death and perturbed calcium homeostasis have also been described 
in peripheral lymphocytes from AD patients (Parshad et al., 1996; Eckert et al., 1997a, 1998, 2000; Gasparini et al., 1998).

In order to close the gap between studies using neuronal cell lines transfected with PS1 mutations, neurons from mutant PS1 transgenic animals and peripheral cells of AD patients, we investigated lymphocytes from mice transgenic for FAD-specific PS1 mutations. We chose to study $\mathrm{T}$ lymphocytes in the present study, since they have been used in most of the human studies and have been well characterized in cell death signalling with respect to a number of cell death stimuli, e.g., oxidative stress or dexamethasone (Migliorati et al., 1994; Dumont et al., 1999).

Furthermore, we included three different types of transgenic mice expressing either a human wild-type PS1 transgene (PS1 wt Tg) or a PS1 transgene bearing a single pathogenic mutation at codon M146 (PS1 M146L Tg) or multiple FAD-specific mutations M146L + H163R + A246E + L286V + C410Y (PS1 M5 $\mathrm{Tg}$ ) (Leutner et al., 2000), since the combination of different PS1 mutations shows additive effects on A $\beta$ 1-42 production (Citron et al., 1998). As already shown by others (Holcomb et al., 1998; Chui et al., 1999), transgenic mice expressing mutant PS1 show an elevation in $\mathrm{A} \beta 1-42$, but they do not develop amyloid deposits up to an age of 13 months or older, although neurodegeneration appears to be accelerated (Chui et al., 1999). However, in brains from PS1 M146L and PS1 M5 Tg mice antioxidant defense enzymes were found to be already reduced at an age of 3 months (Leutner et al., 2000).

In our attempt to search for common alterations as seen in neuronal cell culture and peripheral cells from AD patients, we investigated the vulnerability to cell death, the generation of reactive oxygen species (ROS), and the regulation of intracellular calcium in freshly isolated lymphocytes from all three transgenic animals. Since evidence was provided that neuronal cells from PS1 M146KI mice are more vulnerable to cell death exhibiting features of either apoptosis (Guo et al., 1999b) or necrosis (Guo et al., 1999a) and that the two types of cell death can occur simultaneously in cells exposed to the same stimulus (Nicotera et al., 1999), we tested for both, cell death of apoptotic as well as necrotic nature.

Very recently, a molecular link between PS1/2 and the apoptotic pathway has been found (Passer et al., 1999). PS1 seems to interact with Bcl-XL or Bcl-2, both antiapoptotic proteins of the Bcl-2 family, which can modulate the apoptotic cascade by targeting regula- tory proteins to intracellular membranes (Alberici et al., 1999; Passer et al., 1999). Furthermore, evidence has been provided that mutations in PS2 can induce mitochondria-dependent cytochrome c release and Baxmediated apoptosis in transfected cell lines. To test the hypothesis that mutant PS1 can act on mitochondria in a similar way, we isolated mitochondria from the PS1 M5 Tg mice and performed cytochrome c release experiments.

\section{METHODS}

Generation and characterization of transgenic mice. Generation and expression analysis of transgenic mice was described in detail previously (Leutner et al., 2000). In brief, the coding regions of human wild-type PS1 (PS1 wt) or PS1 containing either one (PS1 M146L) or five distinct FAD mutations (M146L, H163R, A246E, L286V, C410Y) (Sherrington et al., 1995) in one expression construct (PS1 M5) were introduced into a genomic construct with the promotor of the murine 3-hydroxy-3-methyl-glutaryl CoA reductase gene (HMG-CR) that shows a strong and ubiquitous expression pattern in peripheral tissues and in the brain (Gautier et al., 1989; Czech et al., 1998). Western blotting analysis of the different transgenic mouse lines revealed a clear expression of human PS1 in brain and peripheral tissues from transgenic animals. A humanspecific antibody (MAB1563, Chemicon) was used for the detection of full-length PS1 and N-terminal fragments (Czech et al., 1998; Leutner et al., 2000).

Heterozygote transgenic (PS1 wt $\mathrm{Tg}, n=11$; PS1 M146L Tg, $n=10$; PS1 M5 Tg, $n=7$ ) and nontransgenic (non- $\mathrm{Tg}, n=10$ ) mice were littermates or subsequent generation siblings. Animals were handled according to the French guidelines for animal care.

Cells. Lymphocytes were prepared from freshly isolated spleens. The spleens were suspended in ice cold RPMI-1640 buffer (Dutch Modification, Life Technologies), homogenized and passed through a mesh (10- $\mu \mathrm{m}$ diameter). After washing the cell suspension several times and lysing erythrocytes in hypotonic buffer for $3 \mathrm{~min}$, $\mathrm{T}$ cells were negatively isolated by binding B cells to magnetic B-cell antibodies (Dynabeads Mouse Pan B, Dynal). The latter were then magnetically removed from the cell suspension according to the manufacturer's protocol. The obtained $\mathrm{T}$ cell fraction $(>85 \%$ CD3-positive $\mathrm{T}$ cells determined by flow cytometry) was then resuspended at $5 \times 10^{5}$ cells $/ \mathrm{ml}$ in complete medium (RPMI-1640 supplemented with $10 \%$ heat-inactivated fetal bovine serum, 
100 Units of penicillin/ml and $0.1 \mathrm{mg}$ streptomycin/ $\mathrm{ml})$.

Induction of cell death. Cells were investigated directly to determine basal parameters ( $0 \mathrm{~h}$ values) or transferred to 48-well plates, and then incubated (humidified atmosphere at $37^{\circ} \mathrm{C}$ and $5 \% \mathrm{CO}_{2}$ ) for 2.5 or $24 \mathrm{~h}$ with cell death-inducing agents to induce cell death or incubated without additional treatment to study spontaneous in vitro cell death. Cell death was induced by different stimuli: 2-deoxy-D-ribose (d-Rib, $10 \mathrm{mM}$ ), $\mathrm{H}_{2} \mathrm{O}_{2}(10 \mu \mathrm{M})$, and dexamethasone (dex, $\left.0.1 \mu \mathrm{M}\right)$.

Visualization of DNA ladder formation. Cells were resuspended in buffer ( $5 \mathrm{mM}$ Tris- $\mathrm{Cl}, \mathrm{pH} 7.4,20 \mathrm{mM}$ EDTA, $0.5 \%$ Triton X-100), and left on ice for $20 \mathrm{~min}$ followed by centrifugation at $27,000 \mathrm{~g}$ for $20 \mathrm{~min}$. The supernatant was extracted with phenol-chloroform and nucleic acids were precipitated with ethanol. After the pellet was resuspended in $1 \%$ RNase without DNase (Roche Diagnostic) then incubated at $37^{\circ} \mathrm{C}$ for $1 \mathrm{~h}$, the samples were separated by $2 \%$ agarose gel electrophoresis. DNA was visualized with ethidium bromide.

Detection of apoptotic cells by flow cytometry. For analyzing the sub-G $\mathrm{G}_{1}$ DNA content, lymphocytes were harvested by centrifugation at the indicated time points and the pellets resuspended in lysis buffer (0.1\% sodium citrate and $0.1 \%$ Triton $X-100)$ containing $50 \mu \mathrm{g} / \mathrm{ml}$ of propidium iodide (all Sigma, Munich, Germany). Samples were stored at $4^{\circ} \mathrm{C}$ for $1-2$ hours before flow cytometry analysis (FACSCalibur, Becton Dickinson) using Cell Quest software. Hypodiploid cells (percentage apoptotic cells) were quantitated in each sample, according to the method of Nicoletti et al. (1991), using the appropriate instrument settings that exclude cellular and necrotic debris. With flow cytometry 10,000 nuclei per measurement were analyzed, which provides very valid quantitative data.

Detection of nucleosomes in cell lysates and cell culture supernatants. Histone-associated DNA fragments were detected with an immunoassay demonstrating the internucleosomal degradation of genomic DNA during apoptosis. The assay is based on the quantitative sandwich-enzyme-immunoassay principle using mouse monoclonal antibodies directed against DNA and histones, respectively. This allows the specific determination of mono- and oligonucleosomes. Cytoplasmic fractions (lysates) and cell culture supernatants $\left(5 \times 10^{4}\right.$ cells $\left./ 200 \mu \mathrm{l}\right)$ were collected at different incubation times $(0 \mathrm{~h}, 24 \mathrm{~h})$, frozen at $-80^{\circ} \mathrm{C}$, then analyzed in the ELISA (correspond to $5 \times 10^{3}$ cell equivalents). Following the protocol for cytochemistry of the Cell Death Detection ELISA ${ }^{\text {PLUS }}$ (Roche, Ger- many) nucleosomes were photometrically visualized at $405 \mathrm{~nm}$ against blank (reference wavelength 492 $\mathrm{nm}$ ). Absorption values (calculated for $5 \times 10^{3}$ cells) of each ELISA were standardized to the positive controls (Positive Control $=1.0$ ). The time-dependent detection of cytoplasmic histone-associated DNA fragments (mono- and oligonucleosomes) confirms the findings by flow cytometry (Eckert et al., 2000). The assay investigating both cytoplasmic fractions (lysates) and cell-culture-supernatants offers the advantage of discriminating between apoptotic and necrotic cell death. Low molecular weight DNA which is built during apoptosis is found only within the cell. As apoptosis proceeds in vitro, however, cells develop secondary in vitro necrosis which is characterized among other things by cell lysis and the appearance of DNA fragments in the supernatant (Watt et al., 1994; Eckert et al., 2000).

ROS detection. The production of reactive oxygen species (ROS) was detected by flow cytometry using Dihydrorhodamine 123 (DHR, Molecular Probes). Cells were suspended in $1 \mathrm{ml}$ HBSS and DHR was added at a final concentration of $10 \mu \mathrm{M}$ and incubated for $15 \mathrm{~min}$ at $37^{\circ} \mathrm{C}$ in a shaking water bath. DHR enters mitochondria and fluoresces when oxidized by ROS, particularly peroxynitrite, to the positively charged rhodamine 123 derivate. The mean fluorescence intensity (MFI) in FL1 (FL1: channel 1 for green fluorescence) was calculated by determining the mean channel number $(\mathrm{MCN})$ of the peak. This MCN value was converted to a linear value for comparative purposes by calculating the antilog of $\mathrm{x}=$ sample mean channel/(total number of channels/number of log decades $)=$ sample mean channel $/(1024 / 4)=$ sample mean channel/256.

Isolation of mitochondria and detection of cytochrome $c$. Isolation of mitochondria was performed according to the methods of Eskes et al. (1998) with slight modifications (Goping et al., 1998). Briefly, the liver was homogenized with a Potter-Elvehjem homogenizer in mitochondrial buffer (Mannitol $210 \mathrm{mM}$, Sucrose 70 $\mathrm{mM}$, Hepes, $10 \mathrm{mM}$, EDTA $1 \mathrm{mM}$ and dithiothreitol $0.5 \mathrm{mM}, \mathrm{pH} 7.5)$ containing $0.45 \%$ BSA and protease inhibitors (Complete, Roche, Germany). The resulting homogenate was centrifuged twice for $3 \mathrm{~min}$ at $1400 \mathrm{~g}$ and then the supernatant was centrifuged for $5 \mathrm{~min}$ at $10,000 \mathrm{~g}$. The pellet was resuspended in mitochondrial buffer and centrifuged again at $1400 \mathrm{~g}$. The supernatant was now centrifuged at $10,000 \mathrm{~g}$ and the pellet resuspended. This mitochondrial fraction was stimulated for $20 \mathrm{~h}$ at $30^{\circ} \mathrm{C}$ with Bax $1 \mu \mathrm{m}$ or vehicle. Equal amounts of mitochondrial pellets and supernatant 
a

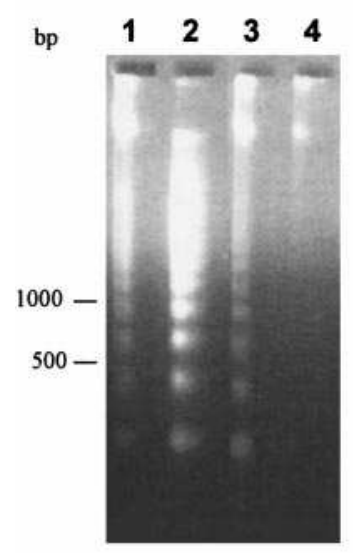

b
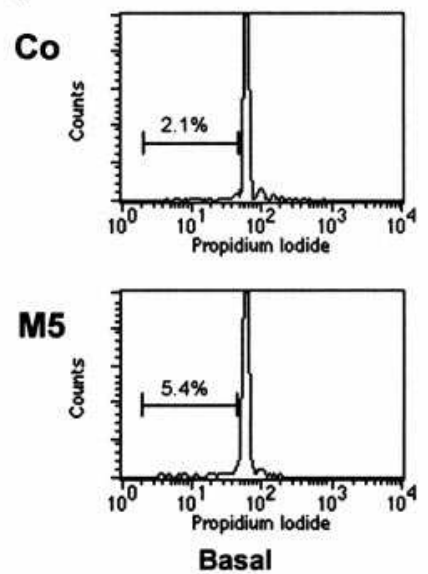
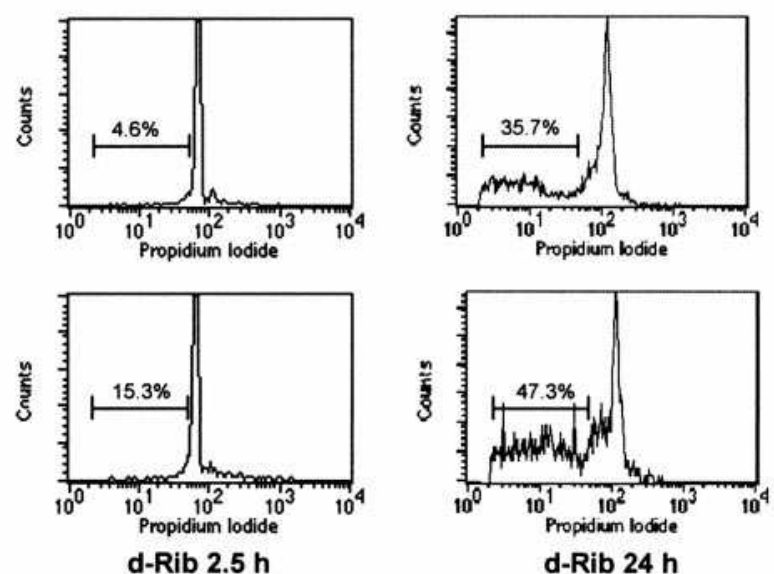

FIG. 1. Apoptotic cell death pattern in lymphocytes from mice. (a) DNA ladder formation (left margin, size) is detectable after incubation of lymphocytes for $24 \mathrm{~h}$ (lane 1, spontaneous in vitro apoptosis; lane 2, dexamethasone-induced DNA ladder; lane 3, $d$-Rib-induced DNA ladder) in contrast to freshly isolated cells (lane 4, control cells, $0 \mathrm{~h}$ ). Data are from a typical experiment replicated three times with lymphocytes from different groups. (b) Apoptotic cell death was assessed by propidium iodide staining and flow cytometry. DNA histograms of lymphocytes indicate basal levels of apoptotic cells (left) or after treatment with d-Rib for $2.5 \mathrm{~h}$ (center) and $24 \mathrm{~h}$ (right), respectively. Upper panel shows histograms from non-Tg control mice (Co), lower panel from PS1 M5 Tg mice (M5). Values represent the portion of apoptotic cells (sub-G 1 peak). DNA histograms represent a typical experiment with cells from one animal. The group differences of the corresponding experiments are presented in Figs. 2a and 3.

fractions were subjected to 18\% SDS-PAGE gel electrophoresis and analyzed by Western blotting. The primary antibody was a 1:300 dilution of a mouse monoclonal antibody against cytochrome c (clone 7H8.2C12, PharMingen, Hamburg, Germany). Western blots were performed with horseradish peroxidase-conjugated anti-mouse IgG using chemiluminescence Western blotting reagents (Amersham Pharmacia Biotech, Buckinghamshire, UK).

ELISA immunoassay for cytochrome c was performed with the commercially available kit Quantikine $M$ from R\&D Systems (Wiesbaden-Nordenstadt, Germany) following the manufacturer's instructions. This assay is able to detect mouse cytochrome $c$ in subcellular fractions and in supernatants after release from isolated mitochondria. Detected levels of cytochrome c were expressed as ng cytochrome c/mg protein.

Calcium measurement. Fura-2 fluorescence of T-cell suspensions was measured using the SLM-Aminco Luminescence Spectrometer as previously described (Eckert et al., 1997a). Cells were loaded with $3 \mu \mathrm{M}$ Fura 2-AM (Molecular Probes) for 30-40 min. After incubation, cells were washed several times with HBSS buffer (Sigma) to remove external dye. The ratio of the fluorescence emission $(510 \mathrm{~nm})$ using two different excitation wavelengths ( 340 and $380 \mathrm{~nm}$ ) was used to determine $\left[\mathrm{Ca}^{2+}\right]_{\mathrm{i}}$ using the formula: $\left[\mathrm{Ca}^{2+}\right]_{\mathrm{i}}=K_{\mathrm{d}}$ $\left[\left(R-R_{\min }\right) /\left(R_{\max }-R\right)\right]\left(F_{0} / F_{\mathrm{s}}\right)$. The mitogen phytohemagglutinin (PHA-P, Sigma) at a final concentration of $15 \mu \mathrm{g} / \mathrm{ml}$ was used to stimulate $\mathrm{Ca}^{2+}$ signalling of $\mathrm{T}$ lymphocytes. $\mathrm{Ca}^{2+}$ responses to PHA are expressed as $\Delta\left[\mathrm{Ca}^{2+}\right]_{i}$, which is the maximal increase in $\left[\mathrm{Ca}^{2+}\right]_{\mathrm{i}}$ over baseline.

Statistics. Data are given as mean \pm SEM. For statistical comparison, Student's $t$ test, one- or two-way ANOVA followed by Tukey's post hoc test were used. $P$ Values smaller than 0.05 were considered to be statistically significant.

\section{RESULTS}

We evaluated apoptotic cell death in lymphocytes by flow cytometry analysis using instrument settings that are specific for the detection of apoptotic DNA fragments. We determined the accumulation of apoptotic cells under basal conditions (Fig. 1b, left panel) or after 2.5 and $24 \mathrm{~h}$ in the absence or presence of cell death triggering agents (Fig. 1b, center and right panel). To induce cell death we used various stimuli, which are known to trigger apoptosis in lymphocytes: dexamethasone (dex) (Migliorati et al., 1994), hydrogen peroxide $\left(\mathrm{H}_{2} \mathrm{O}_{2}\right)$ (Dumont et al., 1999), and 2-de- 

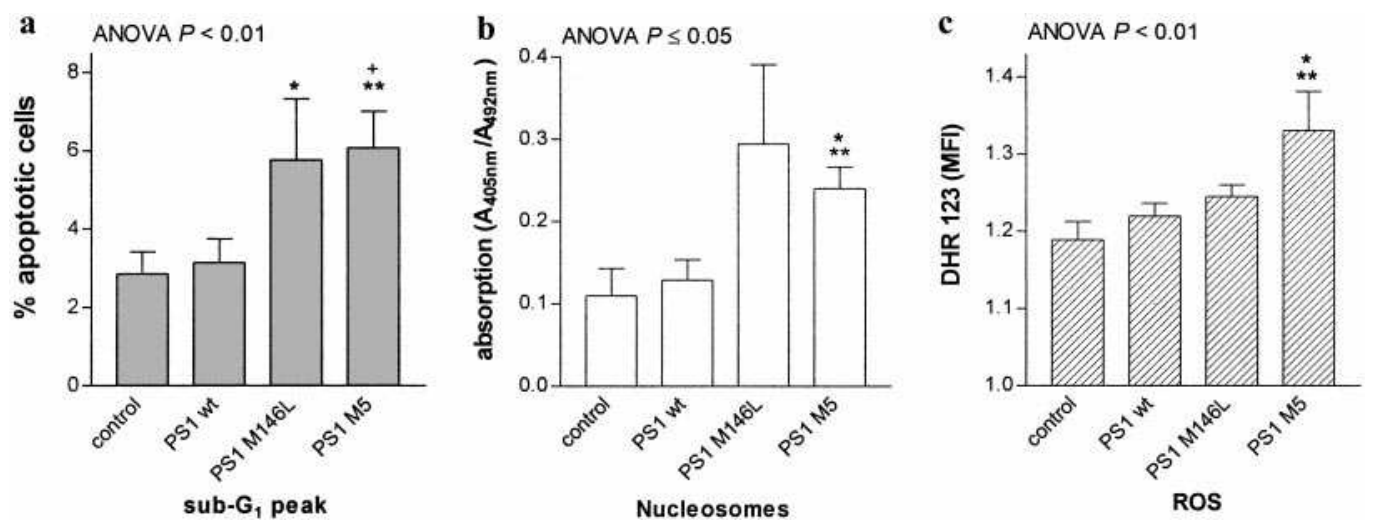

FIG. 2. Basal levels of apoptotic DNA fragmentation and ROS levels are elevated in mice with PS1 mutations. T cells from non-Tg control mice are not significantly different from PS1 wt Tg mice. Data represent mean values and SEM from 6-10 experiments, each representing an individual animal. (a) Apoptotic cell death was assessed by propidium iodide staining and flow cytometry. Lymphocytes from PS1 M146L Tg and PS1 M5 Tg mice show considerable elevations of basal levels of apoptotic cells compared to freshly isolated T cells from non-Tg control and PS1 wt Tg mice $\left(P<0.01\right.$, ANOVA): ${ }^{*} P<0.05$, ${ }^{* *} P<0.01$ vs control; ${ }^{+} P<0.05$ vs PS1 wt Tg. (b) Levels of apoptotic nucleosomes quantitated by CDD ELISA ${ }^{\text {PLUS }}$. Apoptotic nucleosomes (indicated by absorption values referring to $5 \times 10^{3}$ cells per well performed in triplicates) are elevated in lymphocytes from PS1 M5 Tg mice $\left(P \leq 0.05\right.$, ANOVA): ${ }^{*}<0.05$ vs non-Tg control, ${ }^{* *} P=0.01$ vs PS1 wt Tg mice. (c) There are significantly more ROS in T cells from PS1 M5 Tg mice $\left(P<0.01\right.$, ANOVA): ${ }^{*}<0.05$ vs PS1 wt Tg; ${ }^{* *} P<0.01$ vs non-Tg control. ROS levels were evaluated by flow cytometry using dihydrorhodamine 123 (DHR) staining.

oxy-D-ribose (d-Rib) (Eckert et al., 1998). The latter induces oxidative stress and apoptosis in lymphocytes by depletion of the intracellular pool of reduced glutathione (Kletsas et al., 1998). Already after $2.5 \mathrm{~h}$ exposure to d-Rib, an increase of apoptotic cell death was detectable in lymphocytes from individuals of several groups (Fig. 1b, center), which was further enhanced after treatment for $24 \mathrm{~h}$ (Fig. 1b, right panel). A similar cell death pattern was also observed for spontaneous in vitro apoptosis (without additional treatment) and after stimulation with dex or $\mathrm{H}_{2} \mathrm{O}_{2}$ (data not shown). To further confirm the apoptotic nature of cell death, DNA laddering of nuclear fragmentation was assessed in lymphocytes from individuals of several mouse lines. Figure 1a shows a representative experiment.

In flow cytometry analysis, freshly isolated lymphocytes from mice expressing mutant PS1 (PS1 M146L and PS1 M5) showed significantly enhanced basal levels of apoptotic cells compared to T cells from PS1 wt $\mathrm{Tg}$ and nontransgenic (non-Tg) littermate controls (Fig. 2a). These findings could be confirmed in an additional assay detecting cytosolic nucleosomes built during apoptotic cell death (Fig. 2b). Thereby, cells from PS1 mutant Tg mice exhibited a two- to threefold increase in apoptotic features (Figs. $2 \mathrm{a}$ and $2 \mathrm{~b}$ ). To elucidate the postulated relationship between PS1 mutations and oxidative stress, we additionally deter- mined basal ROS levels in lymphocytes from PS1 Tg and non-Tg mice. We could demonstrate that basal levels of ROS in lymphocytes were significantly increased in mice with multiple mutations (Fig. 2c). These results are not unexpected, since as already mentioned the combination of different PS1 mutations enhances $A \beta$ 1-42 production, which can further lead to free radical generation and oxidative stress.

Next, we studied DNA fragmentation in vitro after $2.5 \mathrm{~h}$ incubation. Lymphocytes from PS1 M5 Tg mice showed significantly enhanced vulnerability to spontaneous in vitro apoptosis and after exposure to dex or oxidative stress (d-Rib, $\mathrm{H}_{2} \mathrm{O}_{2}$ ) for $2.5 \mathrm{~h}$ when compared with that of T cells from PS1 wt Tg and non-Tg control mice, whereas the vulnerability of the single mutation PS1 M146L was not markedly increased (Fig. 3). In none of the conditions investigated, lymphocytes from PS1 wt Tg mice were significantly different from non-Tg littermate control mice. The difference in vulnerability of T cells from PS1 M5 Tg mice to apoptotic cell death was still salient $24 \mathrm{~h}$ after exposure to cell death-inducing agents (Fig. 4). Again, multiple mutations in PS1 showed much more apoptotic cells than cells from PS1 wt Tg and control mice did (Fig. 4, white bars). In contrast to the results showing the rapid DNA fragmentation after $2.5 \mathrm{~h}$ (Fig. 3), apoptotic nucleosomes in T cells from PS1 M146L Tg mice also tended to be elevated after $24 \mathrm{~h}$, but less extensively 

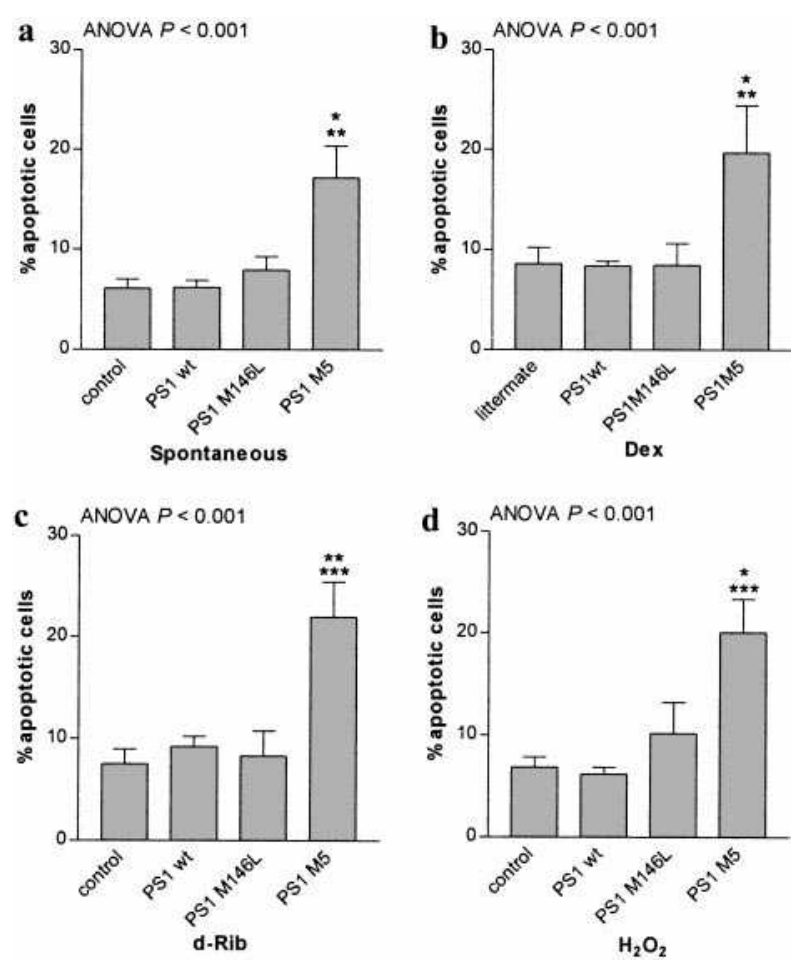

FIG. 3. Lymphocytes from transgenic mice bearing multiple PS1 mutations already show elevated apoptotic vulnerability to cell death after $2.5 \mathrm{~h}$ incubation compared to cells from non-Tg control and PS1 wt Tg mice. Flow cytometry was used to determine percentage apoptotic cells. Data represent mean values and SEM from 7-11 experiments, each representing an individual animal. (a) Spontaneous in vitro apoptosis $\left(P<0.001\right.$, ANOVA): ${ }^{*} P<0.05$ vs PS1 M146L Tg; ${ }^{* *} P<0.01$ vs non-Tg control and PS1 wt Tg. (b) Dexamethasone-induced apoptosis (Dex, $0.1 \mu \mathrm{M} ; P<0.001$, ANOVA); ${ }^{*} P<0.05$ vs non-Tg littermate control and PS1 M146L Tg; ${ }^{* *} P<0.01$ vs PS1 wt Tg. (c) 2-Deoxy-D-ribose-induced apoptotic cell death (d-Rib, $10 \mathrm{mM} ; P<0.001$, ANOVA); ${ }^{* * P}<0.01$ vs PS1 wt Tg and PS1 M146L Tg; ${ }^{* * *} \mathrm{P}<0.001$ vs non-Tg littermate control. (d) $\mathrm{H}_{2} \mathrm{O}_{2}$ induced apoptotic cell death $\left(10 \mu \mathrm{M} ; P<0.001\right.$, ANOVA); ${ }^{*} P<0.05$ vs PS1 M146L Tg; ${ }^{* *} P<0.001$ vs non-Tg littermate control and PS1 wt $\mathrm{Tg}$.

than those with multiple mutations and not significantly when compared to PS1 wt Tg mice $(P=0.06$, for spontaneous and $\mathrm{H}_{2} \mathrm{O}_{2}$-induced apoptosis) or non-Tg littermates (Fig. 4, white bars).

Furthermore, we determined whether changes in the susceptibility to necrotic cell death also take place in lymphocytes from PS1 mutant mice. Therefore, we evaluated nucleosomes in the supernatants of the in vitro cultures of lymphocytes (Fig. 4). Examination of in vitro necrosis showed significantly enhanced susceptibility of lymphocytes from both PS1 M146L and PS1 M5 Tg mice in contrast to PS1 wt Tg mice (Fig. 4, black bars). Again, cell death in PS1 M5 Tg lympho- cytes was higher than in T cells bearing a single PS1 mutation suggesting that the combination of several FAD-related mutations strengthens the effects of PS1 on cell death regulation. No differences were found between PS1 wt Tg and non-Tg control mice for this paradigm.

To determine whether mitochondrial dysfunction is involved in mechanisms leading to increased susceptibility to cell death in PS1 Tg mice due to FADspecific mutations, we isolated mitochondrial fractions from liver tissue and assayed these for the presence of cytochrome c (Fig. 5). No significant differences in the basal levels of intramitochondrial cytochrome c (Fig. 5a) or of released cytochrome c (Fig. 5b) were found between PS1 M5 Tg mice, which show the highest vulnerability to apoptosis, and control mice. In addition, cytochrome c release following stimulation of isolated mitochondria with Bax was not different between the mice groups (Figs. 5a and 5b). Regardless of whether PS1 can act at the level of the mitochondria or not, our results demonstrate that PS1 mutations have negligible effects on cytochrome c release in mitochondria from young adult PS1 Tg mice.

We next investigated the intracellular calcium regulation in $\mathrm{T}$ cells from transgenic animals. Measurement of basal $\left[\mathrm{Ca}^{2+}\right]_{i}$ in $\mathrm{T}$ lymphocytes from mice revealed no differences among the groups (Fig. 6a). However, after stimulation with the mitogen phytohemagglutinin (PHA) the elevation in $\left[\mathrm{Ca}^{2+}\right]_{\mathrm{i}}\left(\Delta \mathrm{Ca}^{2+}\right.$ increase) was markedly increased in T cells from PS1 M5 Tg mice compared to that from PS1 wt Tg and non-Tg control mice (Fig. 6b). Once the calcium peak was reached, it also remained considerably increased in mutant PS1 M5 carrying T cells (data not shown), possibly representing a calcium overloading process in PS1 mutant cells. In lymphocytes, the PHA-induced course of $\mathrm{Ca}^{2+}$ increase is dominated by $\mathrm{Ca}^{2+}$ influx, which is activated by initial $\mathrm{Ca}^{2+}$ release from the ER (Zweifach \& Lewis, 1993). Interestingly, the coupling between these events appears to be markedly impaired in lymphocytes bearing mutant PS1 from both PS1 M146L Tg and PS1 M5 Tg mice, since the time interval to reach the maximum calcium peak concentration following PHA stimulation $\left(t_{\max }\right)$ was significantly increased (Fig. 6c). Again, the combination of PS1 mutations in PS1 M5 Tg mice shows additive effects on the latency of the calcium peak. These changes were significantly different from the much faster calcium responses in lymphocytes from PS1 wt Tg mice and littermate controls (Fig. 6c). 

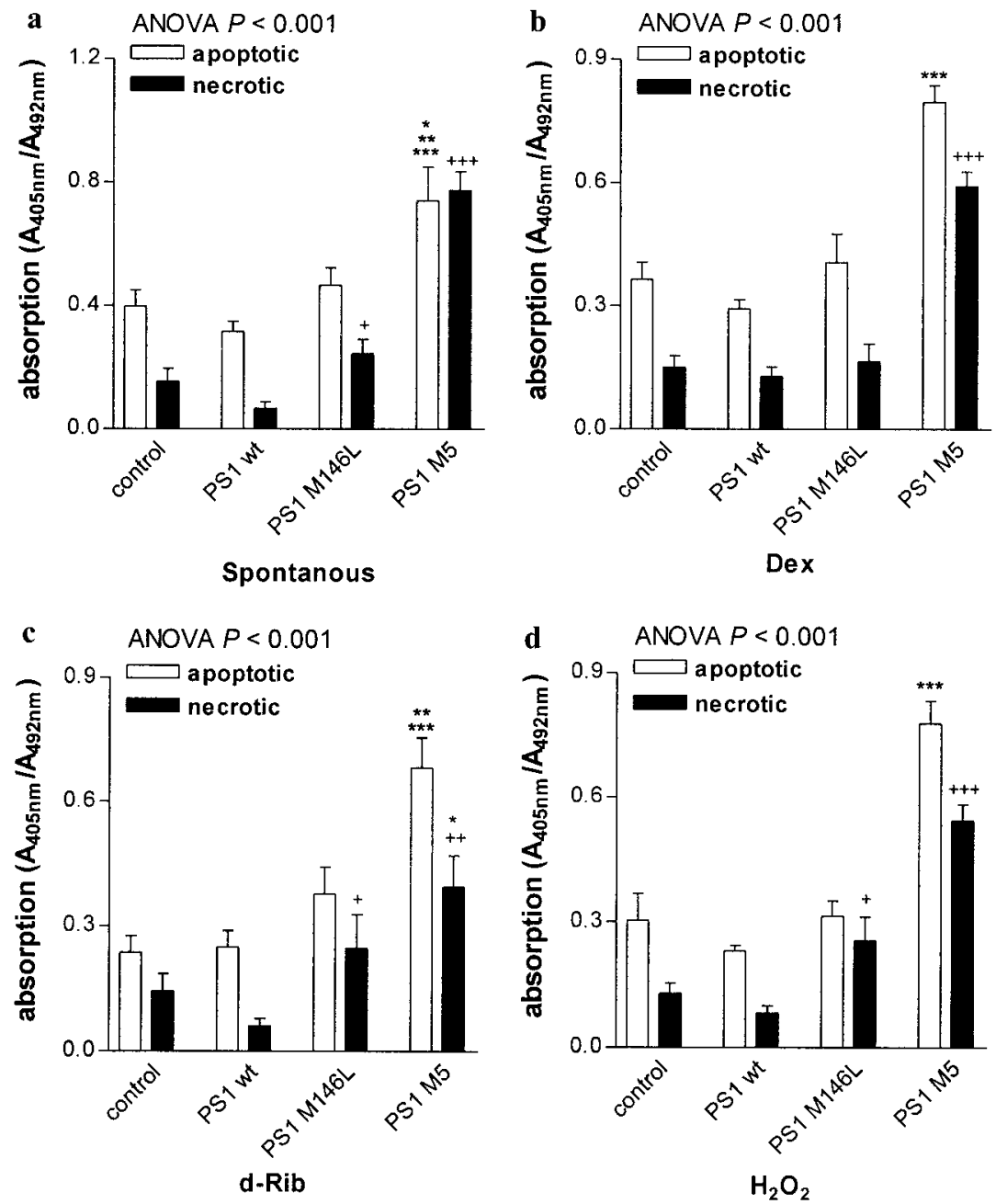

FIG. 4. Lymphocytes from transgenic mice bearing single or multiple PS1 mutations have increased vulnerability to necrotic cell death after $24 \mathrm{~h}$ incubation. Again, cells from PS1 M5 Tg mice show greater apoptosis after $24 \mathrm{~h}$ than do cells from non-Tg littermate control and PS1 wt Tg mice. Low molecular weight fragmented DNA was detected in cytoplasmic fractions and cell-culture-supernatants after 24 h. Data represent mean values and SEM from 7-11 experiments, each representing an individual animal. For all conditions (a-d) two-way ANOVA revealed significant differences between mice groups and cell death pattern: $P<0.001$. (a) Spontaneous in vitro cell death (apoptosis: ${ }^{*} P<0.05$ vs PS1 M146L Tg; ${ }^{* *} P<0.01$ vs non-Tg control; ${ }^{* * *} P<0.001$ vs PS1 wt Tg; necrosis: ${ }^{+} P<0.05$ vs PS1 wt Tg; ${ }^{+++} P<0.001$ vs all). (b) Dexamethasone-induced cell death (Dex, $0.1 \mu \mathrm{M}$; apoptosis: ${ }^{* * *} P<0.001$ vs all; necrosis: ${ }^{+++} P<0.001$ vs all). (c) 2 -Deoxy-D-ribose-induced cell death (d-Rib, $10 \mathrm{mM}$; apoptosis: ${ }^{* *} P<0.01$ vs PS1 M146L Tg; ${ }^{* *} P<0.001$ vs non-Tg control and PS1 wt Tg; necrosis: ${ }^{*} P<0.05$ vs non-Tg control; ${ }^{+} \mathrm{P}<0.05,{ }^{++} \mathrm{P}<0.01$ vs PS1 wt Tg). (d) $\mathrm{H}_{2} \mathrm{O}_{2}$-induced cell death $\left(10 \mu \mathrm{M}\right.$; apoptosis: ${ }^{* *} \mathrm{P}<0.001$ vs all; necrosis: ${ }^{+} \mathrm{P}<0.05$ vs PS1 wt $\mathrm{Tg}^{,}{ }^{+++} \mathrm{P}<0.001$ vs all).

\section{DISCUSSION}

Oxidative stress, mitochondrial function, and intracellular calcium regulation are early and important contributors to either apoptotic or necrotic cell death. In our present study we investigated mechanisms of oxidative stress and oxidative stress-induced cell death in lymphocytes of young adult transgenic mice carrying either a single or multiple human Alzheimer- linked PS1 mutations. Consistent with the rationale that different PS1 mutations within the same molecule cause more dysfunction and higher $\mathrm{A} \beta$ 1-42 levels than one alone (Citron et al., 1998), we found a stronger accumulation of ROS in lymphocytes from mice carrying multiple PS1 mutations (PS1 M5 Tg). These results are in accordance with findings showing reduced activities of cytosolic superoxide dismutase and glutathione reductase in the brain of the same trans- 
a

Mitochondrial Cyt C
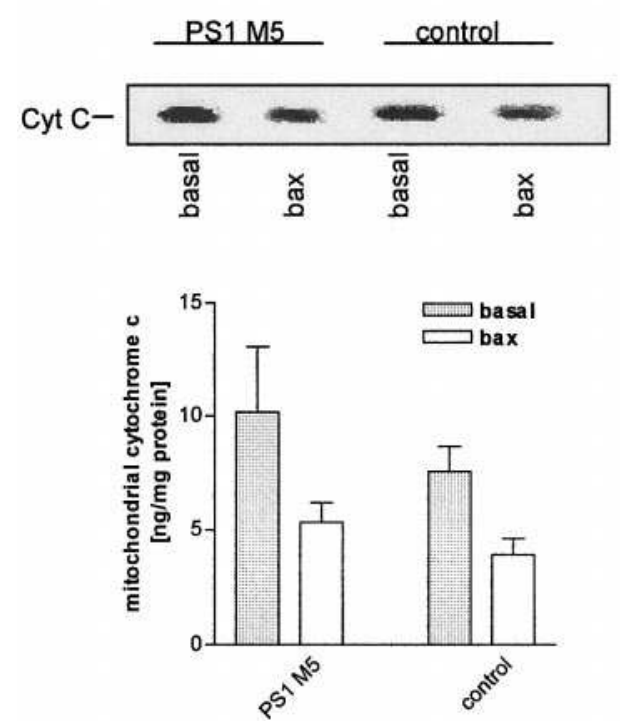

b Cyt $\mathrm{C}$ release
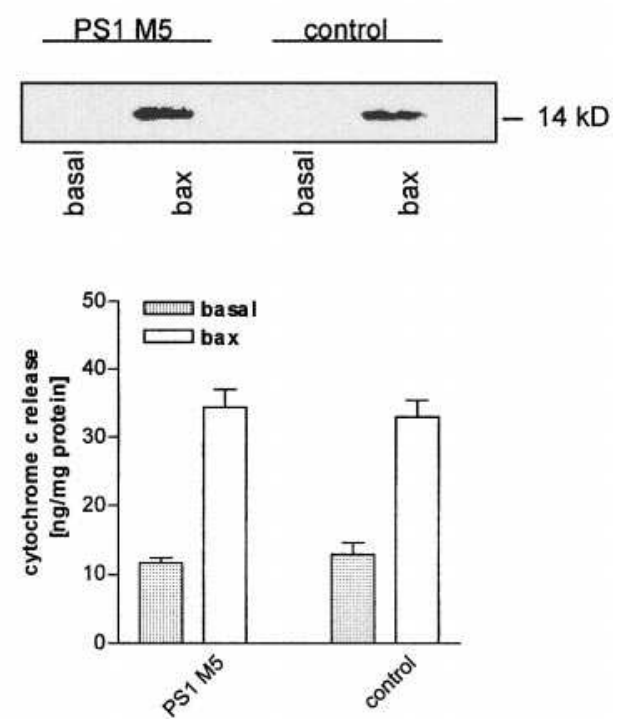

FIG. 5. Mitochondrial cytochrome c (Cyt C) and Bax-induced (bax) cytochrome c release from isolated mitochondria does not differ among control and PS1 mutant mice. Mitochondrial fractions and supernatants were run on a 18\% SDS-PAGE gel and assayed for the appearance of Cyt $\mathrm{C}$ by Western blot analysis with an anti-cytochrome $\mathrm{c}$ antibody (upper panel). Cytochrome $\mathrm{c}$ is detected at a molecular weight of $\sim 15 \mathrm{kDa}$. In addition, mouse cytochrome c was quantitatively evaluated by ELISA immunoassay in subcellular fractions and in supernatants (lower panel). Data represent mean values and SEM from seven or eight experiments, each representing an individual animal. (a) Basal levels of cytochrome $\mathrm{c}$ and after stimulation with Bax are similar within mitochondria from non-Tg control and PS1 M5 Tg mice. (b) Release of cytochrome c from mitochondria after stimulation with Bax is not different between non-Tg control and PS1 M5 Tg mice.

genic animals (Leutner et al., 2000) and with data from lymphoblasts of FAD patients with mutant PS1 indicating altered levels of reduced glutathione (Cecchi et al., 1999). They are further consistent with findings demonstrating increased vulnerability of PS1 M146KI hippocampal neurons to lipid peroxidation after exposure to $\mathrm{A} \beta$ (Guo et al., 1999b). Our results additionally indicate that comparable disturbances in ROS metabolism due to PS1 mutations can be detected not only in brain but also in peripheral cells such as lymphocytes. Furthermore, lymphocytes from mutant PS1 Tg mice showed an increased susceptibility to cell death compared to $\mathrm{T}$ cells from PS1 wt $\mathrm{Tg}$ mice or non-Tg littermate controls. Already basal levels of apoptotic cells were elevated in PS1 mutant mice. However, spontaneous or activation-induced in vitro apoptosis was extremely increased in lymphocytes from PS1 M5 Tg mice, but not in PS1 M146L Tg mice. In contrast, necrotic-type cell death was elevated in both PS1 M146L and PS1 M5 Tg mice. These findings suggest that PS1 may enhance vulnerability to both types of cell death. Mainly the severity of insult, cellular homeostasis, and preexisting damage may deter- mine the pattern of cell death to be either more apoptotic or more necrotic in nature. This is also consistent with findings showing that PS1 mutations on the one hand sensitizes PC12 cells, neuroblastoma cells, or primary neurons from PS1 M146KI mice to apoptosis (Guo et al., 1997, 1999b; Tanii et al., 2000) and on the other hand make hippocampal cells from PS1 M146KI mice more vulnerable to necrotic insults (Guo et al., 1999a). Very interestingly, some evidence is provided that a similarly increased vulnerability to oxidative stress-induced DNA damage is present in lymphocytes from FAD patients bearing PS1 mutations (Parshad et al., 1996). Additional experiments, e.g., assessing caspase- 3 activation, might be needed to clarify whether cell death as observed in lymphocytes from PS1 transgenic animals or from FAD patients belongs to the apoptotic or necrotic pathway.

Growing evidence is provided that mutant PS1 sensitizes cells to apoptosis induced by different stimuli. Whether this is solely due to an increased production of neurotoxic A $\beta$ 1-42 by mutant PS1 or whether additional mechanisms are involved, is not known. Very recent findings demonstrate that the PS2 muta- 

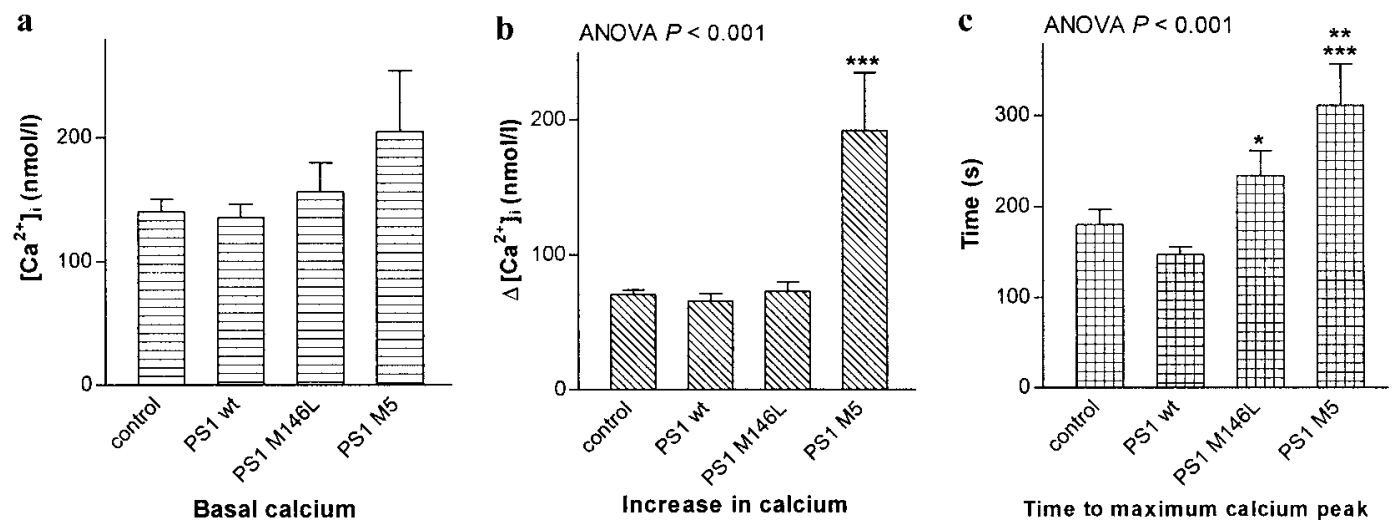

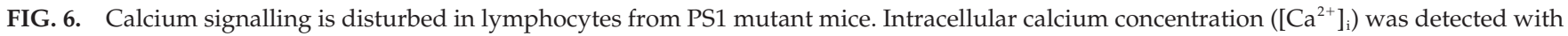
the fluorescent dye fura-2. Data represent mean values and SEM from 6-10 experiments, each representing an individual animal. (a) Basal calcium levels are not different in non- $\mathrm{Tg}$ control and PS1 Tg mice. (b) Increase in calcium $\left(\Delta\left[\mathrm{Ca}^{2+}\right]_{\mathrm{i}}\right.$ : response over baseline) after stimulation with PHA is significantly enhanced in lymphocytes from mice bearing multiple PS1 mutations $\left(P<0.001\right.$, ANOVA): ${ }^{* *} P<0.01$ vs all. (c) Lymphocytes from mice with a single or multiple PS1 mutations exhibit a delayed calcium response to PHA. Time to reach maximum calcium peak after stimulation is significantly greater in PS1 M146L and PS1 M5 Tg mice, respectively $\left(P<0.001\right.$, ANOVA): ${ }^{* *} P<0.01$ vs non-Tg control; ${ }^{*} P<0.05$ and ${ }^{* *} P<0.001$ vs PS1 wt Tg mice.

tion N141I, which also increases the basal apoptotic activity of cells (Wolozin et al., 1996; Janicki \& Monteiro, 1997), induced cytochrome c release from mitochondria in transfected human kidney 293 cells (Passer et al., 1999). Therefore, in the present study, we asked whether mutant PS1 may act in a similar way on mitochondria through an increased release of cytochrome c. Our experiments did not show changed basal cytochrome c levels within mitochondria of young adult mice transgenic for mutant PS1 as it has been demonstrated for mutant PS2 N141I in transfected cells. On the one hand, it is possible that FADrelated PS1 mutations exacerbate the cell suicide program by mechanisms different from that of mutant PS2. On the other hand, an association between PS1 and Bcl-2 (Alberici et al., 1999) or Bcl-XL, another antiapoptotic member of the Bcl-2 family (Passer et al., 1999), has been found. Therefore, redistribution of cytochrome $c$, one of the best known downstream activators of the apoptotic cascade, could be one of the crucial events influenced by PS1/Bcl-2 interaction. However, the molecular mechanisms by which FAD PS mutations enhance apoptotic activity in this context are not known. One can speculate that mutant PS1 may generate molecules with proapoptotic activity or may negatively regulate the antiapoptotic effects of Bcl-2 family members, possibly by indirectly regulating the activity of Bax, finally leading to enhanced cytochrome $c$ release in response to an apoptotic signal (Guo et al., 1997; Passer et al., 1999). Since our experiments show that basal cytochrome $\mathrm{c}$ within the mitochondrial membrane is unchanged in PS1 mutant mice, it seems possible that mutant PS1 exerts its cell death-enhancing effect on mitochondria mainly in response to an apoptotic stimulus. This idea is further supported by our findings that T cells from PS1 M5 Tg mice exhibit very high levels of apoptosis after induction of cell death, e.g., with hydrogen peroxide, compared to basal apoptosis without stimulus. Therefore, we investigated in our current study the Bax-induced cytochrome c release from isolated mitochondria. Again, no differences in cytochrome c levels after release from mitochondria were found between PS1 M5 $\mathrm{Tg}$ and non-Tg control mice. Thus, we suggest that a defective in vivo interaction between mutant PS1 and Bcl-2 rather than a disruption of cytochrome $\mathrm{c}$ regulation in general may underlie the FAD-related pathophysiology. Findings from Alberici et al. (1999), which demonstrated a direct cross-talk between these two molecules during apoptosis, are compatible with this view. How FAD-related PS1 mutants finally exert their effects at this level needs further characterization.

Furthermore, the regulation of intracellular calcium, which represents an early event in proliferation and cell death, was altered in lymphocytes bearing PS1 mutations. In accordance, $\mathrm{A} \beta$ peptide and substances that act via calcium release from the ER (thapsigargin) lead to large intracellular calcium increases in PC12 cells expressing mutant PS1 (PS1 L286V) (Guo et al., 1997). To stimulate $\mathrm{Ca}^{2+}$ increase in lymphocytes we used the mitogen PHA that binds to the CD3-receptor 
of $\mathrm{T}$ lymphocytes. The initial phase of this rise is partially mediated by the IP3-dependent calcium release from intracellular stores, whereas the subsequent plateau phase is dominated by calcium influx from the extracellular space through voltage independent calcium channels (Zweifach \& Lewis, 1993; Eckert et al., 1997a). In addition to an increased $\mathrm{Ca}^{2+}$ response to PHA, a marked delay of the calcium peak after mitogenic stimulation of $\mathrm{T}$ lymphocytes carrying single or multiple mutant PS1 could be observed. PS1 is mainly localized in ER membranes, where it colocalizes with ryanodine receptors (Chan et al., 2000), and it is very likely that the presenilins in conjunction with calsenilin have a major function in regulating ER calcium levels (Buxbaum et al., 1998). On this basis, one may speculate that PS1 mutations could also alter the function of calcium channels, including store-operated calcium channels, since there is a close interaction of the ER and these channels. Findings from Barrow et al. (2000), which demonstrated an abnormal, late, and very slow increase in calcium evoked by depolarization in hippocampal neurons from mutant PS1 M146L transgenic mice, are further compatible with this view.

Interestingly, enhanced vulnerability to cell death is also an important factor of sporadic AD, which makes up the majority of the patients $(>90 \%)$. While histological studies in postmortem brain tissue indicate enhanced features of apoptotic cell death such as DNA fragmentation (Li et al., 1997; Cotman, 1998; Masliah et al., 1998; Stadelmann et al., 1999), evidences for an enhanced cellular vulnerability to apoptosis mainly originates from studies using lymphocytes from sporadic AD patients (Parshad et al., 1996; Eckert et al., 1998; Mecocci et al., 1998). Very importantly, our present findings in lymphocytes from PS1 mutant transgenic mice mirror very well comparable findings in lymphocytes from AD patients (Parshad et al., 1996; Eckert et al., 1998). Apoptosis under baseline conditions and after oxidative stress was significantly more pronounced in AD patients not only compared to aged nondemented controls but also compared to patients with vascular dementia (Eckert et al., 2000). Furthermore, the time delay of the calcium peak in PS1 mutant $\mathrm{T}$ cells matches our and others observations on lymphocytes of AD patients (Bondy et al., 1996; Eckert et al., 1997a). Again, this change was not seen in vascular dementia cases (Eckert et al., 1997b). An increased IP3-mediated calcium release was identified in peripheral cells from sporadic as well as from FAD cases with PS1 mutations (Ito et al., 1994; Etcheberrigaray et al., 1998; Bhagavan et al., 1998). Since all of these specific alterations can be picked up in lympho- cytes from sporadic AD patients or from FAD patients as well as from transgenic mice carrying FAD-specific mutations, it seems possible that enhanced cellular vulnerability to cell death, disturbed calcium regulation, and enhanced oxidative stress represent a common pathological pathway for sporadic and familial AD caused by mutations in PS1.

In summary, our findings indicate that disturbances in the metabolism of ROS inside cells, abnormal calcium homeostasis, and increased susceptibility to cell death may contribute to the pathogenic mechanisms of PS1 mutations in vivo. This study further demonstrates that it is possible to bridge the gap between research using transgenic animal models or cell culture systems and studies using tissue from AD patients.

\section{ACKNOWLEDGMENTS}

The authors thank Drs L. Pradier and G. Tremp for helpful discussion as well as Dr. P. Gallix and his team for support with the animals. We appreciate excellent technical assistance by J. LeGuern, G. Ret, and B. Schombert. This work was supported by grants from Fonds der Chemischen Industrie and from the Dr. Robert Pfleger Stiftung.

\section{REFERENCES}

Alberici, A., Moratto, D., Benussi, L., Gasparini, L., Ghidoni, R., Gatta, L. B., Finazzi, D., Frisoni, G. B., Trabucchi, M., Growdon, J. H., Nitsch, R. M., \& Binetti, G. (1999) Presenilin 1 protein directly interacts with Bcl-2. J. Biol. Chem. 274, 30764-30769.

Barrow, P. A., Empson, R. M., Gladwell, S. J., Anderson, C. M., Killick, R., Yu, X., Jefferys, J. G., \& Duff, K. (2000) Functional phenotype in transgenic mice expressing mutant human presenilin-1. Neurobiol. Dis. 7, 119-126.

Bhagavan, S., Ibarreta, D., Ma, D., Kozikowski, A. P., \& Etcheberrigaray, R. (1998) Restoration of TEA-induced calcium responses in fibroblasts from Alzheimer's disease patients by a PKC activator. Neurobiol. Dis. 5, 177-187.

Bondy, B., Hofmann, M., Muller-Spahn, F., Witzko, M., \& Hock, C. (1996) The PHA-induced calcium signal in lymphocytes is altered after blockade of $\mathrm{K}(+)$-channels in Alzheimer's disease. J. Psychiatr. Res. 30, 217-227.

Buxbaum, J. D., Choi, E. K., Luo, Y., Lilliehook, C., Crowley, A. C., Merriam, D. E., \& Wasco, W. (1998) Calsenilin: A calcium-binding protein that interacts with the presenilins and regulates the levels of a presenilin fragment. Nat. Med. 4, 1177-1181.

Cecchi, C., Latorraca, S., Sorbi, S., Iantomasi, T., Favilli, F., Vincenzini, M. T., \& Liguri, G. (1999) Gluthatione level is altered in lymphoblasts from patients with familial Alzheimer's disease. Neurosci. Lett. 275, 152-154.

Chan, S. L., Mayne, M., Holden, C. P., Geiger, J. D., \& Mattson, M. P. (2000) Presenilin-1 mutations increase levels of ryanodine recep- 
tors and calcium release in PC12 cells and cortical neurons. J. Biol. Chem. 275, 18195-18200.

Chui, D. H., Tanahashi, H., Ozawa, K., Ikeda, S., Checler, F., Ueda, O., Suzuki, H., Araki, W., Inoue, H., Shirotani, K., Takahashi, K., Gallyas, F., \& Tabira, T. (1999) Transgenic mice with Alzheimer presenilin 1 mutations show accelerated neurodegeneration without amyloid plaque formation. Nat. Med. 5, 560-564.

Citron, M., Eckman, C. B., Diehl, T. S., Corcoran, C., Ostaszewski, B. L., Xia, W., Levesque, G., St. George, H., Younkin, S. G., \& Selkoe, D. J. (1998) Additive effects of PS1 and APP mutations on secretion of the 42-residue amyloid beta-protein. Neurobiol. Dis. 5, 107-116.

Citron, M., Westaway, D., Xia, W., Carlson, G., Diehl, T., Levesque, G., Johnson-Wood, K., Lee, M., Seubert, P., Davis, A., Kholodenko, D., Motter, R., Sherrington, R., Perry, B., Yao, H., Strome, R., Lieberburg, I., Rommens, J., Kim, S., Schenk, D., Fraser, P., St. George, H., \& Selkoe, D. J. (1997) Mutant presenilins of Alzheimer's disease increase production of 42-residue amyloid betaprotein in both transfected cells and transgenic mice. Nat. Med. 3, 67-72.

Cotman, C. W. (1998) Apoptosis decision cascades and neuronal degeneration in Alzheimer's disease. Neurobiol. Aging 19, S29S32.

Czech, C., Lesort, M., Tremp, G., Terro, F., Blanchard, V., Schombert, B., Carpentier, N., Dreisler, S., Bonici, B., Takashima, A., Moussaoui, S., Hugon, J., \& Pradier, L. (1998) Characterization of human presenilin 1 transgenic rats: Increased sensitivity to apoptosis in primary neuronal cultures. Neuroscience 87, 325-336.

Czech, C., Tremp, G., \& Pradier, L. (2000) Presenilins and Alzheimer's disease: Biological functions and pathogenic mechanisms. Prog. Neurobiol. 60, 363-384.

Dumont, A., Hehner, S. P., Hofmann, T. G., Ueffing, M., Droge, W., \& Schmitz, M. L. (1999) Hydrogen peroxide-induced apoptosis is CD95-independent, requires the release of mitochondria-derived reactive oxygen species and the activation of NF-kappaB. Oncogene 18, 747-57.

Eckert, A., Cotman, C. W., Zerfass, R., Hennerici, M., \& Muller, W. E. (1998) Enhanced vulnerability to apoptotic cell death in sporadic Alzheimer's disease. Neuroreport. 9, 2443-2446.

Eckert, A., Forstl, H., Zerfass, R., Hennerici, M., \& Muller, W. E. (1997a) Free intracellular calcium in peripheral cells in Alzheimer's disease. Neurobiol. Aging 18, 281-284.

Eckert, A., Oster, M., Forstl, H., Hennerici, M., \& Muller, W. E. (1997b) Impaired calcium regulation in subcortical vascular encephalopathy. Stroke 28, 1351-1356.

Eckert, A., Oster, M., Zerfass, R., Hennerici, M., \& Müller, W. E. (2000) Elevated levels of fragmented DNA nucleosomes in native and activated lymphocytes indicate an enhanced sensitivity to apoptosis in sporadic Alzheimer's disease: Specific differences to vascular dementia. Dementia, in press.

Eskes, R., Antonsson, B., Osen-Sand, A., Montessuit, S., Richter, C., Sadoul, R., Mazzei, G., Nichols, A., \& Martinou, J. C. (1998) Bax-induced cytochrome $C$ release from mitochondria is independent of the permeability transition pore but highly dependent on Mg2+ ions. J. Cell Biol. 143, 217-224.

Etcheberrigaray, R., Hirashima, N., Nee, L., Prince, J., Govoni, S., Racchi, M., Tanzi, R. E., \& Alkon, D. L. (1998) Calcium responses in fibroblasts from asymptomatic members of Alzheimer's disease families. Neurobiol. Dis. 5, 37-45.

Gasparini, L., Racchi, M., Binetti, G., Trabucchi, M., Solerte, S. B., Alkon, D., Etcheberrigaray, R., Gibson, G., Blass, J., Paoletti, R., \& Govoni, S. (1998) Peripheral markers in testing pathophysiologi- cal hypotheses and diagnosing Alzheimer's disease. FASEB J. 12, 17-34.

Gautier, C., Mehtali, M., \& Lathe, R. (1989) A ubiquitous mammalian expression vector, $\mathrm{pHMG}$, based on a housekeeping gene promoter. Nucleic. Acids. Res. 17, 8389.

Goping, I. S., Gross, A., Lavoie, J. N., Nguyen, M., Jemmerson, R., Roth, K., Korsmeyer, S. J., \& Shore, G. C. (1998) Regulated targeting of BAX to mitochondria. J. Cell Biol. 143, 207-215.

Guo, Q., Fu, W., Sopher, B. L., Miller, M. W., Ware, C. B., Martin, G. M., \& Mattson, M. P. (1999a) Increased vulnerability of hippocampal neurons to excitotoxic necrosis in presenilin-1 mutant knock-in mice. Nat. Med. 5, 101-106.

Guo, Q., Sebastian, L., Sopher, B. L., Miller, M. W., Ware, C. B., Martin, G. M., \& Mattson, M. P. (1999b) Increased vulnerability of hippocampal neurons from presenilin-1 mutant knock-in mice to amyloid beta-peptide toxicity: Central roles of superoxide production and caspase activation. J. Neurochem. 72, 1019-1029.

Guo, Q., Sopher, B. L., Furukawa, K., Pham, D. G., Robinson, N., Martin, G. M., \& Mattson, M. P. (1997) Alzheimer's presenilin mutation sensitizes neural cells to apoptosis induced by trophic factor withdrawal and amyloid beta-peptide: Involvement of calcium and oxyradicals. J. Neurosci. 17, 4212-4222.

Holcomb, L., Gordon, M. N., McGowan, E., Yu, X., Benkovic, S., Jantzen, P., Wright, K., Saad, I., Mueller, R., Morgan, D., Sanders, S., Zehr, C., O'Campo, K., Hardy, J., Prada, C. M., Eckman, C., Younkin, S., Hsiao, K., \& Duff, K. (1998) Accelerated Alzheimertype phenotype in transgenic mice carrying both mutant amyloid precursor protein and presenilin 1 transgenes. Nat. Med. 4, 97-100.

Ito, E., Oka, K., Etcheberrigaray, R., Nelson, T. J., McPhie, D. L., Tofel-Grehl, B., Gibson, G. E., \& Alkon, D. L. (1994) Internal Ca2+ mobilization is altered in fibroblasts from patients with Alzheimer disease. Proc. Natl. Acad. Sci. USA 91, 534-538.

Janicki, S., \& Monteiro, M. J. (1997) Increased apoptosis arising from increased expression of the Alzheimer's disease-associated presenilin-2 mutation (N141I). J. Cell Biol. 139, 485-495.

Kletsas, D., Barbieri, D., Stathakos, D., Botti, B., Bergamini, S., Tomasi, A., Monti, D., Malorni, W., \& Franceschi, C. (1998) The highly reducing sugar 2-deoxy-D-ribose induces apoptosis in human fibroblasts by reduced glutathione depletion and cytoskeletal disruption. Biochem. Biophys. Res. Commun. 243, 416-425.

Leutner, S., Czech, C., Schindowski, K., Touchet, N., Eckert, A., \& Müller, W. E. (2000) Reduced antioxidant enzyme activity in brains of mice transgenic for human presenilin-1 with single or multiple mutations. Neurosci. Lett. 292, 87-90.

Li, W. P., Chan, W. Y., Lai, H. W., \& Yew, D. T. (1997) Terminal dUTP nick end labeling (TUNEL) positive cells in the different regions of the brain in normal aging and Alzheimer patients. $J$. Mol. Neurosci. 8, 75-82.

Masliah, E., Mallory, M., Alford, M., Tanaka, S., \& Hansen, L. A. (1998) Caspase dependent DNA fragmentation might be associated with excitotoxicity in Alzheimer disease. J. Neuropathol. Exp. Neurol. 57, 1041-1052.

Mecocci, P., Polidori, M. C., Ingegni, T., Cherubini, A., Chionne, F., Cecchetti, R., \& Senin, U. (1998) Oxidative damage to DNA in lymphocytes from AD patients. Neurology 51, 1014-1017.

Migliorati, G., Nicoletti, I., Nocentini, G., Pagliacci, M. C., \& Riccardi, C. (1994) Dexamethasone and interleukins modulate apoptosis of murine thymocytes and peripheral T-lymphocytes. Pharmacol. Res. 30, 43-52.

Nicoletti, I., Migliorati, G., Pagliacci, M. C., Grignani, F., \& Riccardi, C. (1991) A rapid and simple method for measuring thymocyte 
apoptosis by propidium iodide staining and flow cytometry. J. Immunol. Methods 139, 271-279.

Nicotera, P., Leist, M., \& Ferrando-May, E. (1999) Apoptosis and necrosis: Different execution of the same death. Biochem. Soc. Symp. 66, 69-73.

Parshad, R. P., Sanford, K. K., Price, F. M., Melnick, L. K., Nee, L. E., Schapiro, M. B., Tarone, R. E., \& Robbins, J. H. (1996) Fluorescent light-induced chromatid breaks distinguish Alzheimer disease cells from normal cells in tissue culture. Proc. Natl. Acad. Sci. USA 93, 5146-5150.

Passer, B. J., Pellegrini, L., Vito, P., Ganjei, J. K., \& D'Adamio, L. (1999) Interaction of Alzheimer's presenilin-1 and presenilin-2 with Bcl-X(L). A potential role in modulating the threshold of cell death. J. Biol. Chem. 274, 24007-24013.

Scheuner, D., Eckman, C., Jensen, M., Song, X., Citron, M., Suzuki, N., Bird, T. D., Hardy, J., Hutton, M., Kukull, W., Larson, E., Levy Lahad, E., Viitanen, M., Peskind, E., Poorkaj, P., Schellenberg, G., Tanzi, R., Wasco, W., Lannfelt, L., Selkoe, D., \& Younkin, S. (1996) Secreted amyloid beta-protein similar to that in the senile plaques of Alzheimer's disease is increased in vivo by the presenilin 1 and 2 and APP mutations linked to familial Alzheimer's disease. Nat. Med. 2, 864-870.

Sherrington, R., Rogaev, E. I., Liang, Y., Rogaeva, E. A., Levesque, G., Ikeda, M., Chi, H., Lin, C., Li, G., \& Holman, K. (1995) Cloning of a gene bearing missense mutations in early-onset familial Alzheimer's disease. Nature 375, 754-760.

Stadelmann, C., Deckwerth, T. L., Srinivasan, A., Bancher, C., Bruck, W., Jellinger, K., \& Lassmann, H. (1999) Activation of caspase-3 in single neurons and autophagic granules of granulovacular degeneration in Alzheimer's disease. Evidence for apoptotic cell death. Am. J. Pathol. 155, 1459-66.

Tanii, H., Ankarcrona, M., Flood, F., Nilsberth, C., Mehta, N. D., Perez-Tur, J., Winblad, B., Benedikz, E., \& Cowburn, R. F. (2000) Alzheimer's disease presenilin-1 exon 9 deletion and L250S mutations sensitize SH-SY5Y neuroblastoma cells to hyperosmotic stress-induced apoptosis. Neuroscience 95, 593-601.

Watt, J. A., Pike, C. J., Walencewicz Wasserman, A. J., \& Cotman, C. W. (1994) Ultrastructural analysis of beta-amyloid-induced apoptosis in cultured hippocampal neurons. Brain Res. 661, 147156.

Wolozin, B., Iwasaki, K., Vito, P., Ganjei, J. K., Lacanê, E., Sunderland, T., Zhao, B. Y., Kusiak, J. W., Wasco, V., \& D'Adamio, L. (1996) Participation of Presenilin 2 in apoptosis: Enhanced basal activity conferred by an Alzheimer mutation. Science 274, 17101713.

Zweifach, A., \& Lewis, R. S. (1993) Mitogen-regulated Ca2+ current of $\mathrm{T}$ lymphocytes is activated by depletion of intracellular $\mathrm{Ca} 2+$ stores. Proc. Natl. Acad. Sci. USA 90, 6295-6299. 